\title{
Announcement and call for papers
}

\section{Conference on Research and Development in Information Retrieval 1986}

The conference will take place 8-10 September 1986 in Pisa, Italy. It is being sponsored by the Consiglio Nazionale delle Ricerche (Italian National Research Council), in cooperation with ACM-SIGIR, AICA-GLIR, BCS-IRSG, and IDI.

Papers are invited on theory, methodology and applications of information retrieval, with particular emphasis on new emerging application areas (office automation, multimedia information, artificial intelligence, etc.). Suggested topics are:

-- systems modelling, development and evaluation

- storage and retrieval techniques

- hardware developments

- complexity problems

- cognitive and semantic models

- mathematical and linguistic models

- user interfaces

- knowledge-based and expert systems

- natural-language processing

- information retrieval in office information systems

- storage and retrieval of multimedia information

- relationship between information retrieval systems and data-base management systems

Authors should submit four copies of a full paper (3,000-5,000 words) to (if from Europe): Dr. Fausto Rabitti, Istituto Elaborazione della Informazione, CNR, via S. Maria 46, 56100 Pisa, Italy; or (if from outside Europe): Prof. Gerard Salton, Computer Science Department, Cornell University, Upson Hall, Ithaca, NY, USA.

For additional information concerning the event, please contact the Conference Secretariat: M. Mennucci, A. Passerotti, C. Peters, IEI-CNR, via S. Maria 46, 56100 Pisa, Italy; tel. (050) 500159; telex 590305 ieicnr i. 